\title{
Case Report: Propriospinal Myoclonus
}

\author{
Catherine Smith, Jason Ramtahal \\ Department of Neurology, South Devon Healthcare NHS Foundation Trust, Torbay, UK \\ Email: catherine.smith31@nhs.net
}

Received 26 April 2014; revised 25 May 2014; accepted 15 June 2014

Copyright (C) 2014 by authors and Scientific Research Publishing Inc.

This work is licensed under the Creative Commons Attribution International License (CC BY).

http://creativecommons.org/licenses/by/4.0/

c) (i) Open Access

\begin{abstract}
This report presents a case of propriospinal myoclonus (PSM) in a previously fit and well female patient who presented with truncal jerking movements when relaxed. Propriospinal myoclonus is a rare condition, of which $\mathbf{8 0} \%$ of the aetiology is idiopathic. It is characterised by involuntary jerking movements of the trunk due to spreading activity via intrinsic propriospinal pathways along the spinal cord. Polymyography is mandatory in the diagnosis of priopriospinal myoclonus however in discerning the differential diagnoses it is inferior to magnetic resonance diffusion tensor imaging. The management of propriospinal myoclonus is dependent on aetiology. Clonazepam has been shown to be effective in the treatment of idiopathic PSM for symptomatic relief.
\end{abstract}

\section{Keywords}

Myoclonus, PSM, Polymyography

\section{Introduction}

Myoclonus is a sudden involuntary movement caused by the contraction of agonist and antagonist muscles generated in any area of the central nervous system [1] [2]. It can be a symptom of non-organic illness or a pathological symptom of a wide range of neurological and systemic disease. Propriospinal myoclonus (PSM) affects muscles in the same myotome and can spread to involve neighbouring spinal segments above or below the origin of stimulation (most commonly the mid-thoracic spinal cord) causing waves of jerking movements up and down the trunk [1].

Propriospinal myoclonus is a rare condition which can be attributed to a cause in approximately $20 \%$ of patients; it can result from spinal trauma, infection, tumours or compression or underlying lesions such as demyelination or arteriovenous malformation [1] [3].

Identification of the underlying cause is the key to treatment, though symptomatic relief has been reported with the use of clonazepam [4].

The aim of this report is to demonstrate a rare case of idiopathic propriospinal myoclonus, the appropriate in- 
vestigations, its diagnosis and management.

\section{Case Report}

A 39-year-old lady with no significant past medical or surgical history was referred to the consultant neurologist by her general practitioner with a two month history of jerking in her trunk occurring mainly when sitting or relaxed. The jerking was absent when laying down or when sitting upright, controlling her core muscles. Of note in this lady's family history is that her sister has dystonia for which she had been treated with botulinum toxin.

When seen in the neurology clinic three months later her condition had worsened and rhythmic contractions of her abdominal muscles were now occurring constantly on a daily basis. The movements appeared to be originating in the left iliopsoas. Legs, hands and head were unaffected and she was able to terminate the movements by lifting her leg, lying down, standing or tensing her abdominal muscles. This was associated with aching legs, particularly the thighs. Neurological examination was normal apart from a tremulous myokymia of her abdominal wall muscles.

The impression was of propriospinal myoclonus and magnetic resonance imaging (MRI) of the brain and whole spine was requested to exclude spinal cord pathology such as demyelination or tumour. Bloods were taken for copper and caeruloplasmin to exclude Wilson's disease, antistreptolysin-O titres to exclude paediatric autoimmune neuropsychiatric disorders associated with streptococcal infections (PANDAS) and a blood film to exclude neuroacanthocytosis. All investigations returned as normal. MRI of the head and whole spine showed no evidence of demyelinating disease or a space occupying lesion. Polymyography testing was performed and revealed rhythmic, persistent contractions of the rectus abdominis muscle occurring at six bursts per ten seconds at a steady pace. The rate increased slightly when asked to perform finger tapping and was not abolished by distraction. The contractions were restricted to the abdominal muscles and there was no involvement of or pathophysiological changes in the iliopsoas or quadriceps muscles. Further investigation with upper and lower limb somatosensory evoked potentials was unremarkable.

The patient was started on an increasing dose of clonazepam $1 \mathrm{mg}$ at night for two weeks, building up to a treatment dose of between 4 - $8 \mathrm{mg}$ in divided doses daily. She found that clonazepam was of some benefit in controlling her symptoms but did not abolish the tremor completely. Pregabalin $25 \mathrm{mg}$ at night was added but not tolerated by the patient; the best symptom control was achieved with a twice daily dose of 0.5 mg clonazepam.

\section{Discussion}

This case report describes an interesting case of idiopathic propriospinal myoclonus, a concept which was created in 1993 to describe three patients who presented with nonrhythmic axial myoclonic jerks causing symmetric flexion of the neck, trunk, hips and knees [5]. Since then, attempts have been made to clarify this rare disorder particularly with respect to its presentation, aetiology and optimum management.

An analysis of 60 patients revealed the clinical presentation of PSM typically consists of myoclonic jerks involving abdominal wall muscles which worsen in the lying position, are accompanied by a premonitory sensation and occur most commonly in middle aged, male, patients [4]. This case is interesting in that the patient's symptoms were relieved in the lying position and were not accompanied by premonition.

PSM is presumed to originate from a spinal generator, which elicits activity spreading caudally and rostrally along the spinal cord via intrinsic propriospinal pathways causing waves of jerking movements up and down the trunk [6]. PSM can be psychogenic or organic due to spinal insults such as compression, infection, tumour or demyelination.

Polymyography is considered essential for the diagnosis of PSM, however one study found that the typical electrophysiological pattern described for PSM has also been found in patients with psychogenic axial jerks [7]. A further study investigating the clinical impact of polymyography on the diagnosis of PSM found that polymyographic patterns can be voluntarily mimicked [8]. Clinical distinction between PSM and psychogenic axial jerks is unreliable and therefore additional investigations such as magnetic resonance diffusion tensor imaging (MR-DTI) aid in the diagnosis of PSM [9]. Conventional MRI is often found to be normal in patients, however it may be useful in order to exclude certain aetiologies such as demyelination or tumours. A study evaluating the role of magnetic resonance diffusion tensor imaging and fiber tracking (MR-DTI-FT) illustrated that this mode of investigation is an accurate way of demonstrating tract-specific microstructural abnormalities within the spinal cord [10]. MR-DTI-FT has proved to be more sensitive than MRI in the diagnosis of PSM [4]. 
The treatment of PSM is very much dependent on the aetiology. For example, PSM caused by thoracic disc herniation is best managed surgically whereas in the event of idiopathic or non-organic aetiology, a medical approach with pharmacotherapy is more appropriate [11]. Clonazepam has been reported as the most effective drug to control symptoms of PSM and, indeed, provided symptom relief in this case [4].

A case report presenting a 50-year-old male with repetitive abdominal jerks proposed transcutaneous electrical nerve stimulation (TENS) as a treatment for PSM. Authors postulated that the tactile stimulus might act as inhibitory afferents onto the abnormal inhibitory interneurons at the spinal level [12]. It was found that the patient was able to gradually reduce the intensity of stimulation over a period of time with continued effectiveness. A diagnosis of psychogenic myoclonus was negated in this case by the absence of certain positive findings.

\section{Conclusion}

This clinical report illustrates an interesting and atypical case of PSM. With regards to presentation, the demographic was uncharacteristic and typical exacerbating and relieving factors were absent. Extensive investigation was undertaken in order to determine a cause for the patient's symptoms and results were negative. Diagnosis relies on the clinical picture and EMG, however studies have shown limitations when distinguishing PSM from psychogenic myoclonus and MR-DTI-FT may be more reliable. This was not used in the diagnosis in this case. It is widely accepted that clonazepam is the most effective treatment for idiopathic PSM and symptomatic relief was achieved in this case. TENS has also been proposed as a successful treatment in one case of PSM however further investigation is necessary in order to substantiate this claim.

\section{Acknowledgements}

We would like to acknowledge Dr Kate Doughty as she has had some input for this article.

\section{References}

[1] Lozsadi, D. (2012) Myoclonus: A Pragmatic Approach. Practical Neurology, 12, 215-224. http://dx.doi.org/10.1136/practneurol-2011-000107

[2] Zamidei, L., Bandini, M., Michelagnoli, G., Campostrini, R. and Consales, G. (2010) Propriospinal Myoclonus Following Intrathecal Bupivacaine in Hip Surgery: A Case Report. Minerva Anestesiologica, 76, 290-293.

[3] Bhidayasiri, R. and Tarsy, D. (2012) Propriospinal Myoclonus. Current Clinical Neurology, 26, 192-193.

[4] Roze, E., Bounolleau, P., Ducreux, D., et al. (2009) Propriospinal Myoclonus Revisited. Neurology, 72, $1301-1309$. http://dx.doi.org/10.1212/WNL.0b013e3181a0fd50

[5] Brown, P., Thompson, P.D., Rothwell, J.C., Day, B.L. and Marsden, C.D. (1991) Axial Myoclonus of Propriospinal Origin. Brain, 114, 197-214.

[6] Van der Salm, S.M.A., Koelman, J.H.T.M., Henneke, S., van Rootselaar, A. and Tijssen, M.A.J. (2010) Axial Jerks: A Clinical Spectrum Ranging from Propriospinal to Psychogenic Myoclonus. Journal of Neurology, 257, 1349-1355. http://dx.doi.org/10.1007/s00415-010-5531-6

[7] Erro, R., Bhatia, K.P., Edwards, M.J., Farmer, S.F. and Cordivari, C. (2013) Clinical Diagnosis of Propriospinal Myoclonus Is Unreliable: An Electrophysiologic Study. Movement Disorders, 28, 1868-1873. http://dx.doi.org/10.1002/mds.25627

[8] Suk, Y., Kang, M.D., Young, H. and Sohn, M.D. (2006) Electromyography Patterns of Propriospinal Myoclonus Can Be Mimicked Voluntarily. Movement Disorders, 21, 1241-1244. http://dx.doi.org/10.1002/mds.20927

[9] Gupta, A. and Lang, A.E. (2009) Psychogenic Movement Disorders. Current Opinion in Neurology, 22, 430-436.

[10] Roze, E., Apartis, E., Vidailhet, M., et al. (2007) Propriospinal Myoclonus: Utility of Magnetic Resonance Diffusion Tensor Imaging and Fiber Tracking. Movement Disorders, 22, 1506-1509. http://dx.doi.org/10.1002/mds.21562

[11] Wooyoung, J., Joong-Seok, K., Jin Young, A. and Hee-Tae, K. (2012) Reversible Propriospinal Myoclonus Due to Thoracic Disc Herniation: Long-Term Follow-Up. Journal of the Neurological Sciences, 313, 32-34. http://dx.doi.org/10.1016/j.jns.2011.09.036

[12] Maltete, D., Verdure, P., Roze, E., et al. (2008) TENS for the Treatment of Propriospinal Myoclonus. Movement Disorders, 23, 2256-2257. http://dx.doi.org/10.1002/mds.22315 
Scientific Research Publishing (SCIRP) is one of the largest Open Access journal publishers. It is currently publishing more than 200 open access, online, peer-reviewed journals covering a wide range of academic disciplines. SCIRP serves the worldwide academic communities and contributes to the progress and application of science with its publication.

Other selected journals from SCIRP are listed as below. Submit your manuscript to us via either submit@scirp.org or Online Submission Portal.
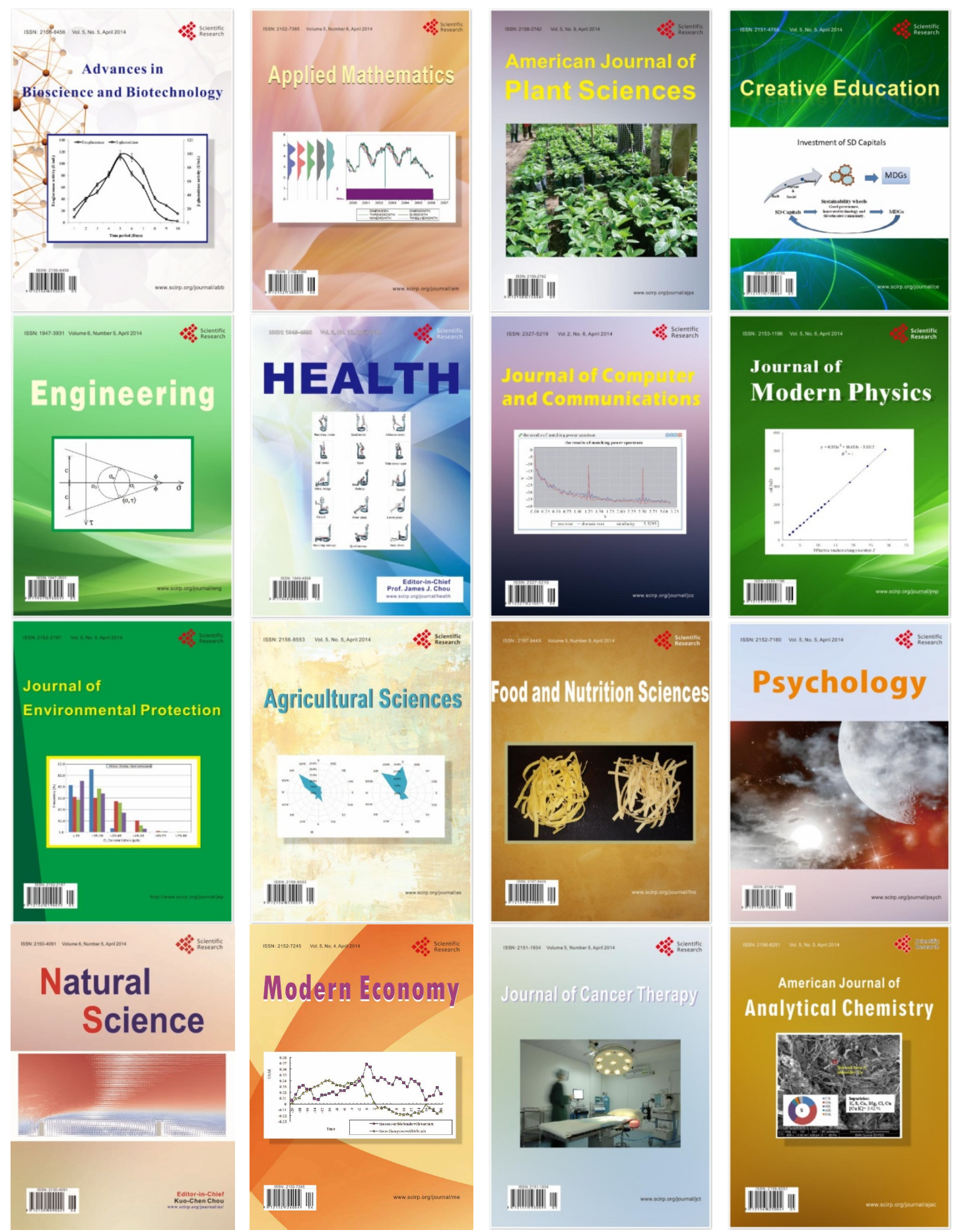